\title{
Effects of Pd Addition on the Electrochemical Properties of MgNi
}

\author{
Tiejun Ma Yuji Hatano Takayuki Abe Kuniaki Watanabe \\ Hydrogen Isotope Research Center, Toyama University \\ Gofuku 3190, Toyama 930-8555, Japan
}

(Received J anuary 14, 2003; Accepted J anuary 23, 2004)

\begin{abstract}
Two kinds of Pd-modified MgNi were prepared: sample I, ball-milling Pd (1, 6 and10 mol\%) with amorphous MgNi for $10 \mathrm{~min}, 2 \mathrm{hr}$ and $10 \mathrm{hr}$ respectively, and sample II, ball-milling $10 \mathrm{~mol} \% \mathrm{Pd}$ with $\mathrm{Mg}_{2} \mathrm{Ni}$ and $\mathrm{Ni}$ for $80 \mathrm{hr}$. Effects of Pd addition on electrochemical properties of MgNi were investigated. For sample I, effects of Pd depended on both Pd ratio and the time of ball-milling. During ball-milling, Pd became amorphous and distributed uniformly on the surface of MgNi powder. At $6 \mathrm{~mol} \%$ and $10 \mathrm{~mol} \% \mathrm{Pd}$, the degradation of discharge capacity of MgNi was significantly decreased. As for sample II, cycle life of MgNi was remarkably improved by Pd modification. The roles of $\mathrm{Pd}$ on behavior of $\mathrm{MgNi}$ were analyzed and the improvements of $\mathrm{MgNi}$ properties arising from both modifications by Pd were regarded as prevention of the formation of $\mathrm{Mg}(\mathrm{OH})_{2}$.
\end{abstract}

\section{Introduction}

Amorphous $\mathrm{MgNi}$ is attractive to be used as anode material of rechargeable $\mathrm{Ni} / \mathrm{MH}$ batteries and has been extensively studied ${ }^{1-6)}$. However, the discharge capacity of MgNi decreases rapidly with the cycles ${ }^{1-7)}$ because of the formation of $\mathrm{Mg}(\mathrm{OH})_{2}$ during charge/discharge cycles $^{7)}$. The present authors have found that the formation of $\mathrm{Mg}(\mathrm{OH})_{2}$ is not necessarily due to charge/discharge cycles, but it is simply formed by chemical reactions with electrolyte solution ${ }^{8)}$. More experimental results ${ }^{9,10)}$ suggested that the properties of MgNi would be improved by surface modification and/or bulk modification if the formation of $\mathrm{Mg}(\mathrm{OH})_{2}$ could be inhibited.

Surface modification is an effective method to improve the properties of MgNi. 
Ball-milling graphite with MgNi for short time ${ }^{11-13)}$ and vacuum evaporating carbon on $\mathrm{MgNi}^{14)}$ increased the discharge capacity and cycle life of MgNi. The present authors also found that ball-milling some aromatic compounds such as benzene $\left(\mathrm{C}_{6} \mathrm{H}_{6}\right)$ and perylene $\left(\mathrm{C}_{20} \mathrm{H}_{12}\right)$ increased discharge capacity and/or cycle life of $\mathrm{MgNi}^{15}$. Meanwhile composition modification, such as alloying $\mathrm{Ti}^{6,12,16,17)}, \mathrm{V}^{12,17,18)}, \mathrm{Zr}, \mathrm{Al}^{16)}$, and $\mathrm{Y}^{19)}$ with $\mathrm{MgNi}$, could result in a certain extent of improvement on electrochemical properties of MgNi.

$\mathrm{Pd}$ is one of catalysts studied in metal-hydrogen reaction. For Mg-Ni alloy system, Zaluski et al. ${ }^{20)}$ found that small amount of Pd (less than 1mass\%) addition not only improved the hydrogen absorption kinetics of nanocrystalline $\mathrm{Mg}_{2} \mathrm{Ni}$ at $200^{\circ} \mathrm{C}$, but also caused hydrogen absorption of nanaocrystalline $\mathrm{Mg}_{2} \mathrm{Ni}$ with relatively good kinetics even at room temperature without activation. Kohno et al. ${ }^{21)}$ reported that nano-size Pd particles ball-milled with $\mathrm{Mg}_{2} \mathrm{Ni}$ at 1:1 molar ratio improved the hydrogen storage properties of $\mathrm{Mg}_{2} \mathrm{Ni}$ in alkaline solution. The improvements on $\mathrm{Mg}_{2} \mathrm{Ni}$ by $\mathrm{Pd}$ were attributed to catalyst effect ${ }^{20,21)}$ on hydrogen absorption reaction, but there was no detailed analysis. In this study, two kinds of Pd-modified MgNi were prepared, effects of Pd on electrochemical properties of MgNi were investigated and the roles of Pd on behavior of MgNi were analyzed.

\section{Experimental}

$\mathrm{Mg}_{2} \mathrm{Ni}$ (below 200 mesh) and $\mathrm{Ni}$ (about $3-7 \mu \mathrm{m}$ ) powders was mixed at molar ratio of $1: 1$. Two grams of the mixture powder were put into a chromium steel vessel of $12 \mathrm{~cm}^{3}$ together with eighteen balls of chromium steel (5.5 mm diameter) in argon atmosphere by using a glove box. A planetary ball mill apparatus (Fritsch P5) was used to grind mechanically the mixture powder at a rotation speed of $350 \mathrm{rpm}$. After $80 \mathrm{hr}$ of ball-milling, the MgNi powder was taken out from the vessel and kept in argon.

In this study, two kinds of Pd-modified MgNi were prepared. For sample I, after amorphous MgNi was prepared, pure Pd powder (about $1 \mu \mathrm{m}$ ) at 1, 6 and $10 \mathrm{~mol} \%$ was mixed with $\mathrm{MgNi}$ and ball milled again for $10 \mathrm{~min}, 2 \mathrm{hr}$ and $10 \mathrm{hr}$ under same ball-milling conditions as MgNi preparation. Prepared powders of sample I will be indicated as MgNi- $x \% \mathrm{Pd}$ or MgNi- $x \% \mathrm{Pd}-y \mathrm{hr}(x=1,6,10$ and $y=10 \mathrm{~min}, 2$ and $10 \mathrm{hr}$ ) hereafter. As for Sample II, Pd was mixed with $\mathrm{Mg}_{2} \mathrm{Ni}$ and $\mathrm{Ni}$ in10:45:45 molar ratio, 
then the mixed powder was ball milled for $80 \mathrm{hr}$ under above mentioned conditions and the achieved powder will be called $(\mathrm{MgNi}){ }_{90} \mathrm{Pd}_{10}$ in this paper.

Each of Pd-modified MgNi powder, as well as bare MgNi, was mixed with electrolytic copper powder (2 - $3 \mu \mathrm{m}$ ) in a mass ratio of 1:3 respectively, and $1 \mathrm{~g}$ of such mixture was compressed at $590 \mathrm{MPa}$ for $10 \mathrm{~min}$ into a disc with $10 \mathrm{~mm}$ in diameter in argon. The disc was sandwiched in two nickel meshes and fixed by spot-welding. The charge-discharge characteristics of each sample were measured in $6 \mathrm{M} \mathrm{KOH}$ solution at $25^{\circ} \mathrm{C}$ controlled by a water bath. Two-electrode system was used, where the sandwiched sample disc acted as the negative electrode and sintered $\mathrm{Ni}(\mathrm{OH})_{2} / \mathrm{NiOOH}$ the counter electrode. For each charge-discharge cycle, the sample was charged at 100 $\mathrm{mA} \cdot \mathrm{g}^{-1}$ for $10 \mathrm{hr}$, rested for $5 \mathrm{~min}$ and then discharged at $20 \mathrm{~mA} \cdot \mathrm{g}^{-1}$ to a cut off voltage of $1.0 \mathrm{~V}$.

XRD patterns of testing powders were measured by $\mathrm{Ka}$ radiation of $\mathrm{Cu}$ on PhillipsPW1825 Automated Powder Diffractmeter System at $40 \mathrm{kV}$ and $30 \mathrm{~mA}$. Morphology of powders was observed by Scanning Electron Microscope, Hitachi, S-3500H with Oxford EDS system.

\section{Results}

\section{Sample I}

Fig.1 shows the XRD patterns of sample I containing $6 \mathrm{~mol} \% \mathrm{Pd}$, MgNi-6\%Pd. For bare MgNi, the broad peak around $41.5^{\circ}$ was assigned to amorphous structure and sharp peaks at $44.5^{\circ}$ and $51.8^{\circ}$ were due to Ni remaining in a crystalline state. After 10 min ball-milling with Pd, strong Pd peaks could be observed, indicating that Pd mainly existed as metallic state after short time ball-milling. As ball-milling time increasing, the intensity of Pd

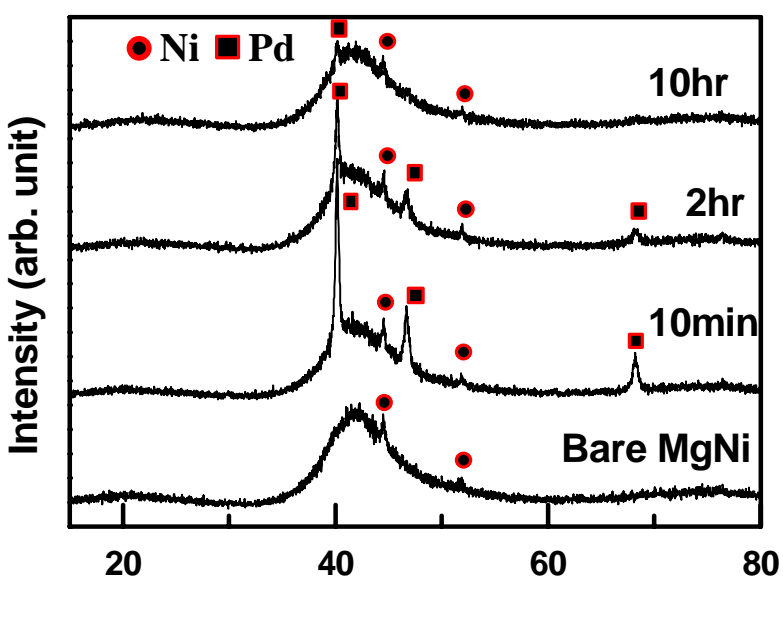

Fig.1 XRD patterns of sample I containing 6mol\% Pd, MgNi-6\%Pd, after ball-milling. 
peaks became weak, and after $10 \mathrm{hr}$ only the strongest peak of $\mathrm{Pd}$ at $40.1^{\circ}$ could be identified, while there was no noticeable change on amorphous peak of MgNi. The XRD patterns of MgNi-1\%Pd and MgNi-10\%Pd showed similar results as MgNi-6\%Pd, even the peaks of Pd for MgNi-1\%Pd were much weaker than those of MgNi-6\%Pd because of lower Pd concentration.

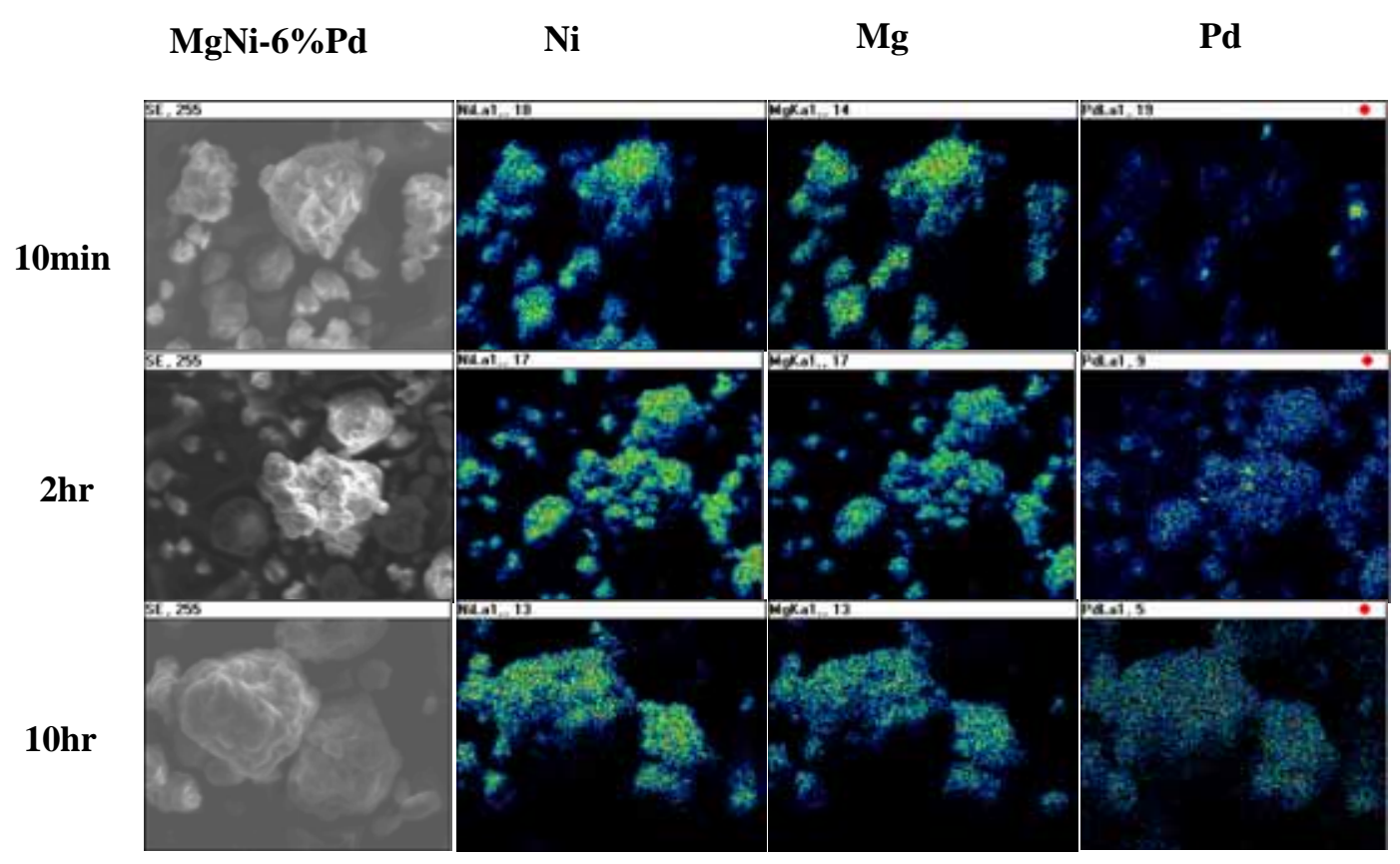

Fig. 2 SEM morphology and concentration distribution of Mg, Ni and Pd for MgNi-6\%Pd after different time of ball-milling.

Fig.2 shows the morphology and concentration distribution of $\mathrm{Mg}$, $\mathrm{Ni}$ and $\mathrm{Pd}$ for MgNi-6\%Pd observed by SEM with EDS. There was no observable difference between the morphologies of powders before (not shown in the figure) and after Pd modification, and distributions of $\mathrm{Mg}$ and $\mathrm{Ni}$ were very uniform for all cases. The distribution of Pd, however, was very different with the time of ball-milling. After 10 min ball-milling with MgNi, Pd was mainly concentrated at some bright points which should be original Pd powders while only small amount of Pd distributed on the surface of MgNi powders. After 2 hr, more Pd distributed rather uniformly on the surface of powders, but there were still some Pd-enriched points. After longer time ball-milling, $10 \mathrm{hr}$, distribution of Pd became very uniform on the surface, and the concentration of Pd measured by EDS 
was some higher than that after $2 \mathrm{hr}$ ball-milling.

Effects of Pd on discharge capacity of MgNi is shown as Fig.3. It was found that the effects of Pd were depended on both Pd ratio and ball-milling time. For MgNi-1\%Pd, as in Fig. 3(a), small amount of Pd had no significant effects on electrochemical properties of MgNi: the discharge capacities for each ball-milling time for the first cycle were almost same as that of bare $\mathrm{MgNi}$, and all decreased with the cycle number at similar rate as bare MgNi. However, the results for $6 \mathrm{~mol} \% \mathrm{Pd}$ modification were very different. In Fig. 3(b), after 10 min ball-milling, the discharge capacity was increased at the first cycle by Pd, but still decreased with the cycles at similar rate as bare MgNi. After $2 \mathrm{hr}$ ball-milling, even discharge capacity for the fist cycle was almost same as the bare one, the degradation of discharge capacity was significantly decreased: at the 10th cycles, the discharge capacity for Pd-modified MgNi was about $220 \mathrm{mAhg}^{-1}$ while about $80 \mathrm{mAhg}^{-1}$ for bare MgNi. The results of $10 \mathrm{hr}$ ball-milling were very similar with those of $2 \mathrm{hr}$. In addition, for $\mathrm{MgNi}-10 \% \mathrm{Pd}$, the results were very similar with those of MgNi-6\%Pd.

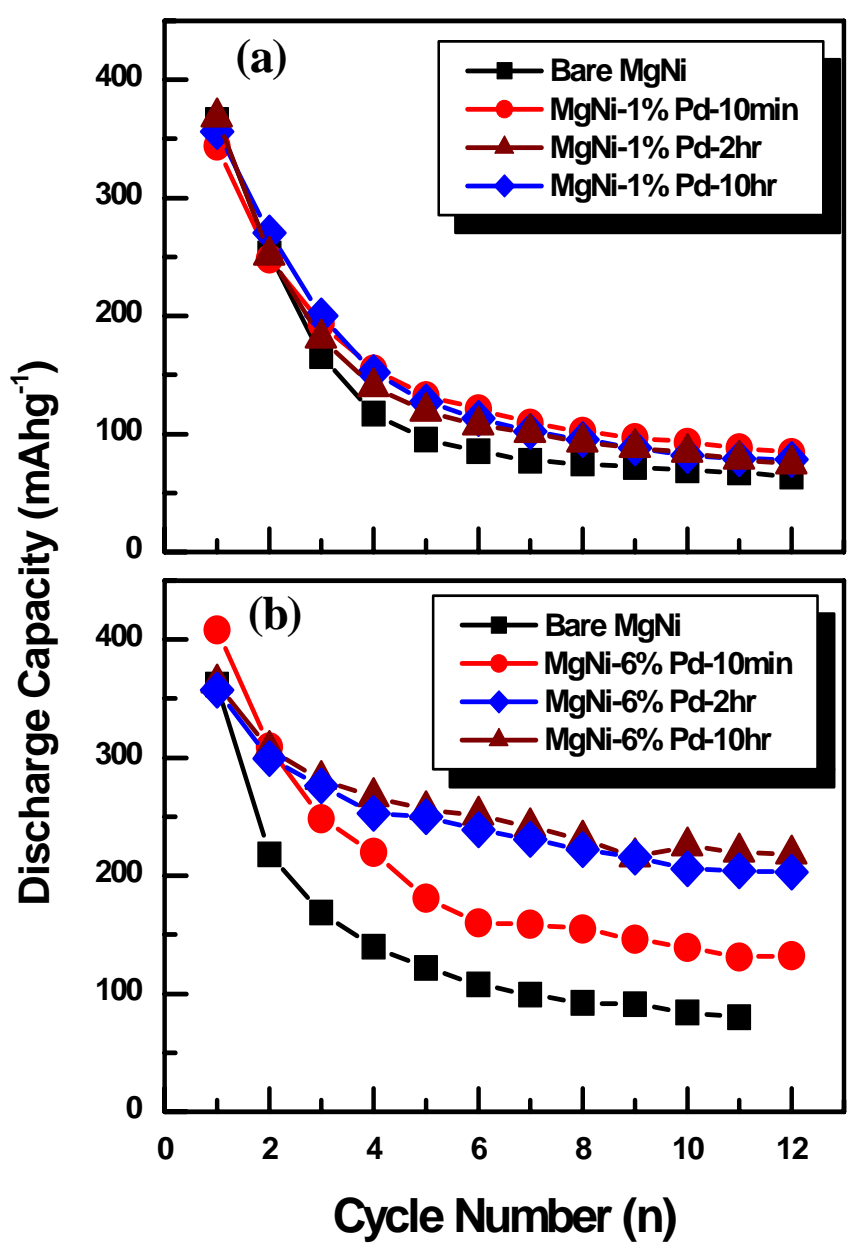

Fig. 3 Effects of Pd on discharge capacity of MgNi for sample I, (a) 1\%Pd and (b) 6\%Pd. 


\section{Sample II}

The XRD pattern of $(\mathrm{MgNi}){ }_{90} \mathrm{Pd}_{10}$, ball-milling $10 \mathrm{~mol} \% \quad \mathrm{Pd}$ with $\mathrm{Mg}_{2} \mathrm{Ni}$ and $\mathrm{Ni}$ for $80 \mathrm{hr}$, was shown in Fig. 4(a). There is no difference comparing with that of bare MgNi, suggesting that 10mol\% Pd addition did not change the amorphous structure of MgNi. For $(\mathrm{MgNi})_{90} \mathrm{Pd}_{10}, \quad \mathrm{Pd}$

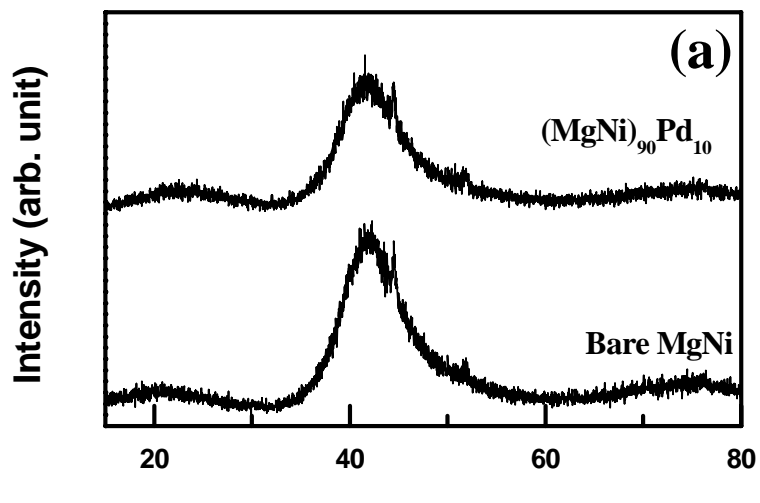
addition caused remarkable improvement on the properties of MgNi as shown in Fig.4(b). Discharge capacity at the first cycle was increased slightly, more importantly, the discharge capacity decreased very slowly with cycles comparing with bare MgNi. For MgNi, after about 10 cycles, the discharge capacity became about $25 \%$ of the first cycle, however, for $(\mathrm{MgNi})_{90} \mathrm{Pd}_{10}$, the discharge capacity, about $250 \mathrm{mAhg}^{-1}$, became

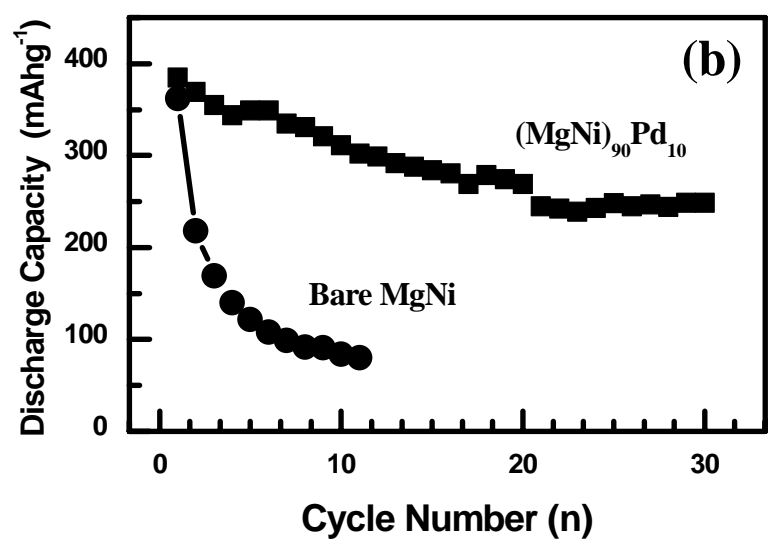

Fig. 4 Effects of Pd of sample II, ball-milling 10mol\%Pd with $\mathrm{Mg}_{2} \mathrm{Ni}$ and $\mathrm{Ni}$ for $80 \mathrm{hr}$, on the properties of MgNi: (a) XRD pattern and (b) discharge capacity. about $60-65 \%$ of the first cycle even after 30 cycles .

\section{Discussion}

It was found that 1 mass\% Pd addition improved the hydrogen absorption kinetics of nanocrystalline $\mathrm{Mg}_{2} \mathrm{Ni}$ even at room temperature ${ }^{20)}$, and high concentration $\mathrm{Pd}$ (50mol\%) increased the discharge capacity and cycle life of $\mathrm{Mg}_{2} \mathrm{Ni}$ in alkaline solution $^{21)}$. In these studies $\mathrm{Pd}$ was regarded as catalyst for hydrogen absorption. However, in this study, $1 \mathrm{~mol} \%$ Pd showed negligible effects on properties of amorphous $\mathrm{MgNi}$ in $6 \mathrm{M} \mathrm{KOH}$ and effects of 6 and 10mol\% Pd were strongly depended on ball-milling time and the method of Pd modification. These results suggest that the roles 
of $\mathrm{Pd}$ on the properties of $\mathrm{MgNi}$ are different with that on $\mathrm{Mg}_{2} \mathrm{Ni}$. In addition, it was found that during ball-milling with MgNi, Pd gradually lost its crystal structure, became into atom group (nanostructure) or atom and dissolved into amorphous $\mathrm{MgNi}$ and/or attached on the surface of MgNi. This transformation seems very crucial for the properties of MgNi.

In our previous studies ${ }^{8-10,14,15)}$, it has been concluded that, 1) the discharge capacity of $\mathrm{MgNi}$ at the first cycle is determined by the amount of hydrogen absorbed during charge process, and 2) cycle life of MgNi could be increased if the formation of $\mathrm{Mg}(\mathrm{OH})_{2}$ were inhabited. In the case of this study, Pd might affect the properties of $\mathrm{MgNi}$ in three possible aspects: 1) Pd itself can absorb and desorb hydrogen during charge/discharge cycle, 2) Pd atoms, distributing on the surface of MgNi powder, acted as catalyst to improve the electron transmission or hydrogen absorption, and 3) Pd atoms in MgNi structure or on the surface could prevent the formation of $\mathrm{Mg}(\mathrm{OH})_{2}$. Some experimental works were carried out to examine which might be the dominant mechanism of the improvements.

The ability of Pd for hydrogen absorption/desorption was measured. Pd powder with same weight as in MgNi-6\%Pd, was ball milled with graphite (total weight of graphite and Pd was 2 gram) for $10 \mathrm{hr}$ under same conditions as $\mathrm{Pd}$ ball-milling with $\mathrm{MgNi}$, and the discharge capacity of Pd-graphite was measured. The results are shown in Fig. 5. A weak broad peak around $45^{\circ}$ was observed from XRD patterns in Fig. 5(b), suggesting
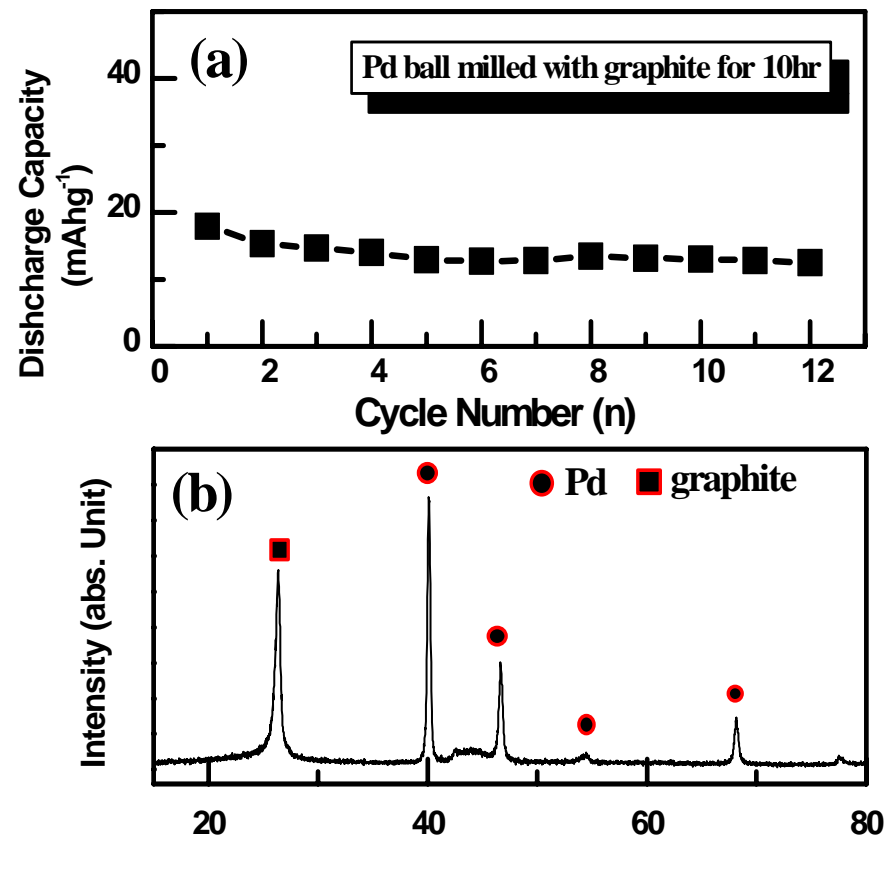

Fig. 5 Discharge capacity and XRD results of Pd ball milled with graphite.

there might be small amount of $\mathrm{Pd}$ and/or graphite transformed into amorphous 
structure, while strong sharp peaks of Pd indicated most of Pd was in crystalline state after ball-milling. This result was very similar with those of MgNi-6\%Pd-10min and MgNi-10\%Pd-10min. Discharge capacity for Pd ball-milling with graphite was about 14-17 mAhg $^{-1}$ for all cycles under current testing conditions as shown in Fig. 5(a) indicating that the ability of hydrogen absorption of crystalline $\mathrm{Pd}$ in $6 \mathrm{M} \mathrm{KOH}$ is much lower than that of MgNi. Meanwhile it was found nanocrsystalline Pd had lower hydrogen absorption ability than grained (crystalline) Pd at 298K ${ }^{22)}$. These results suggest that discharge capacity of Pd is very lower comparing with amorphous $\mathrm{MgNi}$ and the improvement on discharge capacity of Pd-modified MgNi as shown in Fig. 3(b) and Fig 5(b) is not due to the hydrogen absorption ability of Pd.

In order to understand whether Pd on the surface of MgNi causes significant increase in hydrogen absorption ability, a Pd layer was prepared on the surface of MgNi powder by Barrel Sputtering Technique ${ }^{23)}$. Two grams of MgNi were put on the inner wall of the
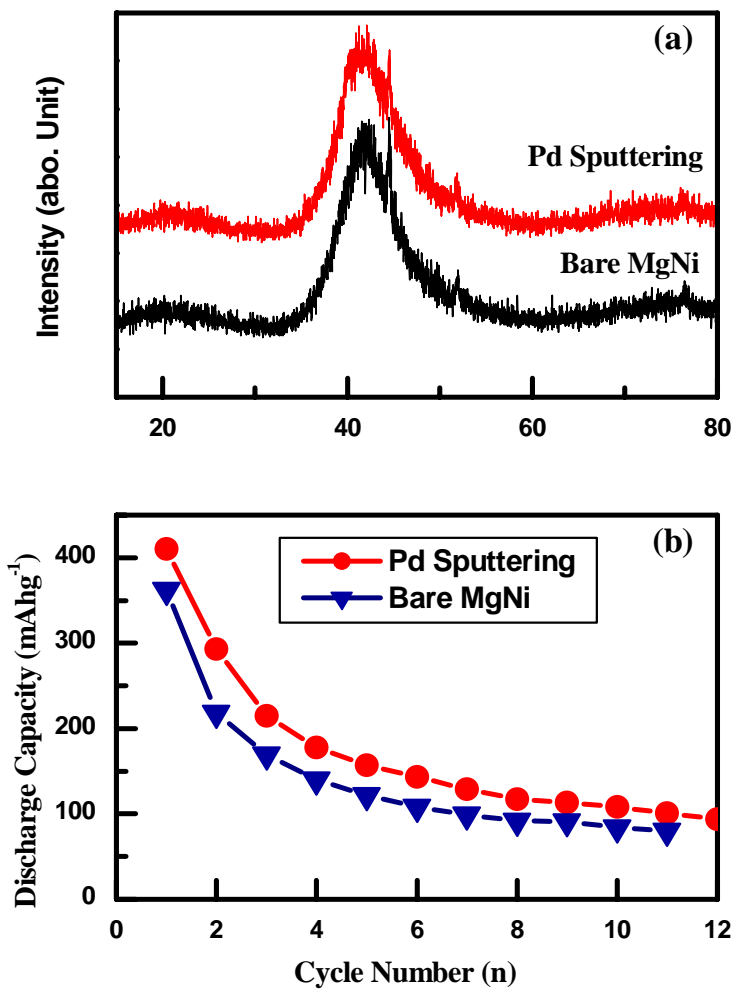

Fig. 6 Discharge capacity and XRD patterns of MgNi after Pd sputtering for 15 min. barrel installed in the sputtering chamber and the chamber was evacuated below $1 \times 10^{-4} \mathrm{~Pa}$ at room temperature. Then the powder was caused to tumble synchronically with the rotation of the barrel. The surface of MgNi powder was first cleaned by argon plasma for $5 \mathrm{~min}$, and then deposited for 15 min by Pd by using a Pd-target at the center of the chamber. The sputtering was carried out by argon plasma generated by RF discharge of $100 \mathrm{~W}$ in an argon flow of $100 \mathrm{sccm}$ at $8 \times 10^{-1} \mathrm{~Pa}$. During the cleaning and sputtering, the rotating speed of the chamber was kept at 100 rpm. After the sputtering, the thickness of this Pd layer was estimated to be in the order of magnitude of $10^{-8} \mathrm{~m}$. 
Effects of deposited Pd on the properties of MgNi are shown in Fig. 6. After sputtering, no difference was found comparing that of bare MgNi from XRD results. The discharge capacity of MgNi was increased by deposited Pd from 360 to $405 \mathrm{mAhg}^{-1}$ at the first cycle, but the degradation of discharge capability had not been suppressed. In our previous research, improved properties of MgNi by carbon evaporation ${ }^{14)}$ was regarded as that surface-applied carbon worked as active positions on the surface of $\mathrm{MgNi}$ powder to improve the electron translation and hydrogen absorption. By Barrel Sputtering Technique, the thin Pd layer on the MgNi surface only increased discharge capacity at the first cycle but did not inhabit the decay of discharge capacity with cycles, which was very similar with that of MgNi-6\%Pd-10min in Fig. 3(b) and carbon modification $^{14)}$, indicating that $\mathrm{Pd}$ atoms on the surface of MgNi acts as active position to improve hydrogen absorption. However, the improvement by $\mathrm{Pd}$ in this mechanism is not significant enough to improve the cycle life as the results observed in this study, such as MgNi-6\%Pd-2hr, MgNi-6\%Pd-10hr and $(\mathrm{MgNi})_{90} \mathrm{Pd}_{10}$.

Another possible explanation for Pd improving properties of $\mathrm{MgNi}$ is that ball-milling Pd with MgNi could prevent the formation of $\mathrm{Mg}(\mathrm{OH})_{2}$. Some testing powders had been immersed in $6 \mathrm{M} \mathrm{KOH}$ solution for $120 \mathrm{hr}$, which is about the time for 4-5 charge/discharge cycles, and XRD patterns were recorded after immersion. The results are shown in Fig. 7. For $6 \mathrm{~mol} \% \mathrm{Pd}$ modified MgNi of sample $\mathbf{I}$, the peaks of

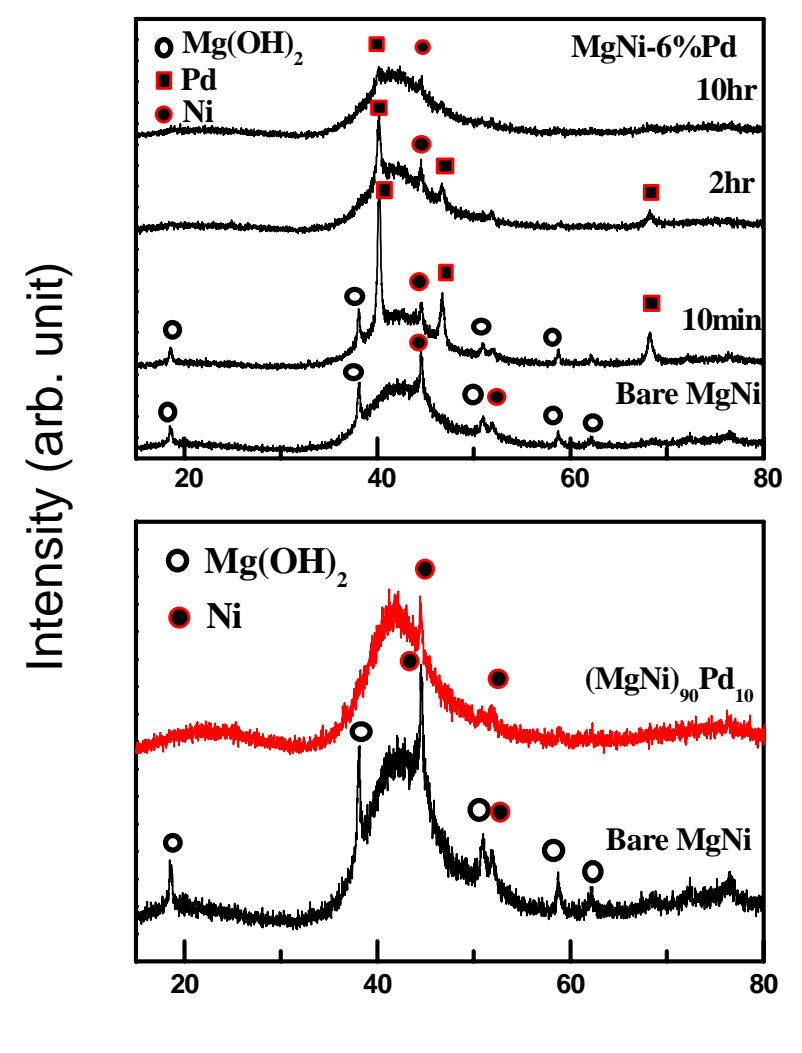

Fig. 7 XRD results of some tested powders after immersion in $6 \mathrm{M} \mathrm{KOH}$ solution for 120 hr: (a) MgNi-6\%Pd of sample I and (b) sample II. $\mathrm{Mg}(\mathrm{OH})_{2}$ was found on the patterns of bare MgNi and MgNi-6mol\%Pd-10min, which showed decreased discharge capacity 
with cycles; while for $2 \mathrm{hr}$ and $10 \mathrm{hr}$ ball-milling, which showed very lower degradation speed than bare MgNi, there was no observable $\mathrm{Mg}(\mathrm{OH})_{2}$ peaks. Combining the results shown in Fig.1, Fig.2, and Fig.3, it can be concluded that uniform distribution of Pd and some extends concentration (at least $6 \mathrm{~mol} \%$ in this study) is very effective to prevent the formation of $\mathrm{Mg}(\mathrm{OH})_{2}$ in alkaline solution. For $(\mathrm{MgNi})_{90} \mathrm{Pd}_{10}$, sample II, after immersion in $6 \mathrm{M} \mathrm{KOH}$ for $120 \mathrm{hr}$, there was no $\mathrm{Mg}(\mathrm{OH})_{2}$ peaks on XRD pattern, indicating that Pd addition was very effective to prevent the formation of $\operatorname{Mg}(\mathrm{OH})_{2}$ on $\mathrm{MgNi}$, and this should be the reason for the remarkable increase in cycle life of MgNi.

$\mathrm{Mg}(\mathrm{OH})_{2}$, formed in alkaline solution, retarded electron-transfer reactions and resulted in the reduction of hydrogen absorption by $\mathrm{MgNi}{ }^{8)}$. Ball-milling compounds ${ }^{15)}$ and graphite ${ }^{11-13)}$ with MgNi protected $\mathrm{Mg}$ atoms on the surface of MgNi powder to form $\mathrm{Mg}(\mathrm{OH})_{2}$ and improved the cycle life of MgNi. Improved properties of $\mathrm{MgNi}$ by $\mathrm{Ti}^{6,16)}$, $\mathrm{Y}^{19)}$ and $\mathrm{V}^{18)}$ addition were also regarded as suppressing the corrosion of $\mathrm{Mg}$ in alkaline media. In this study, even it was found that Pd can absorb some hydrogen and can improve the hydrogen absorption ability of MgNi, the most important effect of Pd on improvement of cycle life of $\mathrm{MgNi}$ might be due to suppressing the $\operatorname{Mg}(\mathrm{OH})_{2}$ formation.

In this study, at same Pd concentration, $10 \mathrm{~mol} \%$, the effects of sample II is better than sample I. This might relate to distribution of Pd atom(s) on surface and/or in lattice of MgNi powder. Even the morphology and XRD patterns of both kinds of Pd-modified MgNi showed very similar results, different modification procedures are very possible to result in some detailed differences on the distribution and/or position of Pd atoms in MgNi powder. Although Pd modification is very effective to prevent the formation of $\mathrm{Mg}(\mathrm{OH})_{2}$, the detailed distribution of $\mathrm{Pd}$ in $\mathrm{MgNi}$, structure of MgNi after modification and how Pd prevents the $\mathrm{Mg}(\mathrm{OH})_{2}$ are still under investigation.

\section{Conclusion}

In this study, two kinds of Pd-modified MgNi were prepared and the effects of Pd addition on electrochemical properties of MgNi were investigated. It was found that, for sample I, after ball-milling Pd (1, 6 and10mol\%) with amorphous MgNi for $10 \mathrm{~min}, 2$ hr and $10 \mathrm{hr}$, effects of Pd depended on both Pd ratio and ball-milling time. During ball-milling, Pd became amorphous and distributed uniformly on the surface of MgNi 
powder. At 6 and 10mol\% $\mathrm{Pd}$, the degradation of discharge capacity of $\mathrm{MgNi}$ was significantly decreased. As for sample II, ball-milling $10 \mathrm{~mol} \% \mathrm{Pd}$ with $\mathrm{Mg}_{2} \mathrm{Ni}$ and $\mathrm{Ni}$ for $80 \mathrm{hr}$, cycle life of $\mathrm{MgNi}$ was remarkably improved by $\mathrm{Pd}$ modification. The improvements, arising from both modifications by Pd were regarded as prevention of the formation of $\mathrm{Mg}(\mathrm{OH})_{2}$.

\section{Acknowledgements}

This work has been supported in part by a Grant-in-Aid for Scientific Research on Priority Areas A of "New Protium Function" of the Ministry of Education, Science, Sports and Culture of Japan. Thanks are offered to Japan Metals and Chemicals Co. for the gift of $\mathrm{Mg}_{2} \mathrm{Ni}$ powder and Matsushita Electric Industrial Co. for positive electrode material. The authors would like to express their sincere thanks to Prof. Ikeno and Prof. Matsuda of Toyama University for the help of SEM analyses.

\section{REFERENCES}

1) Y. Lei, Y. Wu, Q. Yang, J. Wu and Q. Wang: Z. Phys. Chem. Bd. 183 (1994) 379-384.

2) L. Sun, P. Yan, H. K. Liu, D.H. Bradhurst and S. X. Dou: J. alloys and Compounds 293-275 (1999) 536-540.

3) T. Kohno and M. Kanda: J. Electrochem. Soc. 144 (1997) 2384-2388.

4) S. Nohara, N. Fujita, S. G. Zhang, H. Inoue and C. Iwakura: J. Alloys and Compounds 267 (1998) 76-78.

5) D. Sun, Y. Lei, W. Liu, J. Jiang, J. Wu and Q. Wang: J. Alloys and Compounds 231 (1995) 621-624.

6) S. C. Han, P. S. Lee, J. Y. Lee, A. Züttel and L. Schlapbach: J. Alloys and Compounds 306 (2000) 219-226.

7) W. Liu, Y. Lei, D. Sun, J, Wu and Q. Wang: J. Power Sources 58 (1996) 243-247.

8) Y. Hatano, T. Tachikawa, D. Mu, T. Abe, K. Watanabe and S. Morozumi: J. Alloys and Compounds 330-332 ( 2002) 816-820.

9) D. Mu, Y. Hatano, T. Abe and K. Watanabe: J. Alloys and Compounds 334 (2002) 
232-237.

10) T. Abe, T. Tachikawa, Y. Hatano and K. Watanabe: J. of Alloys and Compounds 330-332 ( 2002) 792-795.

11) C. Iwakura, S. Nahara, H. Inoue and Y. Fukumoto: Chem. Commun. (1996) 1831-1832.

12) C. Iwakura, H. Inoue, S. Nohara, R. Shin-ya, S. Kurosaka and K. Miyanohara: J. Alloys and Compounds 330-332 (2202) 636-639.

13) C. Iwakura, H. Inoue, S. G. Zhang and S. Nohrara: J. Alloys and Compounds 293-295 (1999) 653-657.

14) T. Abe, S. Inoue, D. Mu, Y. Hatano and K. Watanabe: J. of Alloys and Compounds, 349 (2003) 279-283.

15) T. Ma, Y. Hatano, T.Abe and K. Watanabe, Material Transactions 43 (2002) 2711-2716.

16) S. C. Han, J. J. Jiang, J.G. Park, K. J. Jang, E. Y. Chin, and J. Y. Lee: J. Alloys and Compounds 285 (1999)L8-L11.

17) C. Iwakura, S. Nohara and H. Inoue: Solid State Inoics 148 (2002)499-502.

18) S. Nohara, K. Hamasaki, S. G. Zhang, H. Inoue and C. Iwakura: J. Alloys and Compounds 280 (1998)104-106.

19) C. Lenain, L. Aymard, L. Dupont, and J-M. Tarascon: J. Alloys and Compounds 292 (1999)84-89.

20) L. Zaluski, A. Zalska, and J. O. Strom-Olsen: J. Alloys and Compounds 217 (1995)245-249.

21) T. Kohno, M. Yamamoto and M. Kanda: J. Alloys and Compounds 293-295 (1999)643-647.

22) T. Kuji, Y. Matsumura, H. Ushida and T. Aizawa: J. Alloys and Compounds 330-332 (2002)718-722

23) M. Hara, Y. Hatano, T, Abe, K. Watanabe, T. Naitoh, S. Ikeno and Y. Honda: J. Nucl. Mater. 320 (2003)265-271. 